\title{
Mentoring in the writing café: identity, belonging and ownership
}

\section{Christie Pritchard}

Plymouth University, UK

\section{Abstract}

The historical legacy of the coffeehouse, the predecessor to the café, is rooted in a culture of community, collaboration and social activity (Ellis, 2004). In January 2014, the Learning Development team at Plymouth University opened the Writing Café; a developmental, creative space that offers the potential to reframe their work outside of the traditional library walls and provides the opportunity to work in partnership with students. Alongside serving great coffee and locally sourced food, the Writing Café is a space for students and staff to meet and discuss writing practices and gain support from the Learning Development team and student Writing Mentors. This paper reports on a small-scale action research project undertaken to investigate to what extent the Writing Mentors benefitted from being partners in this project; as co-designers, advisors, writing mentors, peer supporters and more.

Keywords: identity; writing centres; academic literacies; writing cafe; peer mentoring; students as partners; belonging; third space. 


\section{Introduction}

The rise in the number of writing centres in Higher Education (HE) partly emerged in response to the rapid growth of the sector during the 1990s, and concerns about retention and achievement levels of the new diverse student population (National Committee of Inquiry into Higher Education, 1997; Yeats et al., 2010). The number of students from nontraditional backgrounds, including overseas and mature students increased, bringing with them a much wider range of writing and language abilities (Russell, 2003; LearnHigher, 2009). Writing centres were set up to help address the issue that:

Large numbers of contemporary British undergraduates lack the basic ability to express themselves in writing. (Murray and Kirton, 2006, p.7).

Academic writing is a central feature of $\mathrm{HE}$ and undergraduate and postgraduate students are required to communicate and articulate their thoughts clearly, whilst meeting the objectives of their assignment. Having a solid understanding of the rules and conventions of subject-specific writing also enables students to grow intellectually as they are able to absorb and critically analyse other literature in their discipline (Yeats et al., 2010). As well as standing them in good stead for their time at university, Brauer (2003) also claims that an individual's approach to academic writing has a direct impact on their career opportunities, as good written communication is central to employability with graduate employers increasingly expecting these specialised skills (Avery and Bryan, 2001; Russell, 2003). Writing centres provide students with the opportunity to develop these skills, whilst giving them the confidence to maximise their potential and transition in to university life.

The majority of writing centres are centrally located within institutions, either within Learning Development departments or Study Skills teams, as opposed to within specific faculties. This brings its own challenges as the field of Learning Development is often mistaken for a remedial solution to academic progress (Wingate, 2006; Hill et al., 2010), only beneficial to those who are struggling with the demands of $\mathrm{HE}$ and require additional support. This misconception in part comes from the study skills approach, which defines academic progress, including literacy, as a set of skills which need to be taught in order to fix the deficiencies (Wingate, 2006). However, the majority of writing centres, including the Writing Café, take a much broader view of student support in relation to literacy and are in 
a unique position to create a productive, or 'third space' for learning (Bhabha, 1994; Moje et al., 2004; Hilsdon, 2014. Here, students' own cultures and family lives, or their 'first space', can be used to explore and question the practices of their discipline and the institution; the 'second space' (Bhabha, 1994). By operating outside of their faculty, students are encouraged to explore, critique and question the practices of both their discipline and the institution in general, allowing them to develop their sense of identity, both as a learner and a writer. For Moje, literacies-focused work in the 'third space' offers potential for:

The development of ability to produce and represent knowledge in multiple forms, the ability to analyse how others have represented knowledge and therefore to assess truth claims...to challenge long-standing - even mainstream - claims to knowledge and ultimately, to produce new knowledge that will benefit society. (Moje, 2007, p.33).

Educational research into student writing can be categorised into three main perspectives; study skills, academic socialisation and academic literacies (Lea and Street, 1997). Although they are not mutually exclusive, by adopting the academic literacies approach the Writing Café takes in to account the cultural and contextual components of writing practices, rather than solely focusing on 'good and bad' educational judgements about writing. This approach sees literacies as social practices, where discourses and power are intertwined within the institution and students' learning is 'at the level of epistemology and identities' (Lea and Street, 1997, p.159). Ivanic (1998) argues that writing in HE is not solely concerned with communicating content, but rather a way of aligning ones beliefs and socio-culturally shaped positions, thus students' values and interests and the representation of their self is communicated though the words they write. Students are often required to adapt their active, first person voices, to passive and impersonal forms of writing, which challenge their personal identities (Lea, 1994; Ivanic, 1998). Providing students with a safe space to question these practices, develop their identities and become a student, allows them to make their own meaning and become part of a community of practice (Lave and Wenger, 1991), which is at the heart of the Writing Café's mission. 
Developing a sense of identity as a student is central to an individual's engagement and thus academic success (Wenger, 1998; Jackson, 2003). Engagement is an important notion that enables students to develop a:

Sense of connectedness, affiliation, and belonging, while simultaneously offering rich opportunities for learning and development. (Bensimon, 2009, xxii-xxiii).

Due to this, student engagement agendas are the focus of many institutions nationally (Healey et al., 2014), and Plymouth University has its own commitment with a jointly developed agreement, known as 'Students as Partners' (Plymouth University, 2012). Central to this agreement is the commitment to work and learn together by encouraging and recognising the value of an inclusive community (Plymouth University, 2012). In line with this, and to provide opportunities for engagement with university life, students have been involved with the Writing Café from the beginning of the project. Rather than making individuals 'fit' in to a HE culture, students should have their identity affirmed, honoured and incorporated into the organisations culture (Gallacher et al., 2002; Crossan et al., 2003) which is why the Learning Development team worked with students in the early design stages, facilitating focus groups to ensure the physical design of the space reflected the requirements of their preferred writing areas, and inviting students to become part of a working group to put these designs in to action. The opening of the Writing Café, and its establishment throughout the term, was truly a collaborative achievement. The Writing Mentors were given the freedom and support to initiate and run a number of activities and events which were of interest and benefit to them, including co-presenting at national conferences and organising events to encourage the local community to attend the Writing Café.

\section{The study}

The research was undertaken at Plymouth University by a member of the Learning Development team who jointly co-ordinated the opening and running of the Writing Café. The space attracts both novice and expert writers and provides them with the opportunity to 'overcome the challenges and obstacles in their efforts to write effectively and productively' (Moore, 2003, pg. 333) and aims to reframe the traditional notion that academic writing is a 'solitary, isolated, solely competitive activity' (Grant and Knowles, 
cited in Moore, 2003, pg. 334). In addition to the daily drop-in peer advice available from the Writing Mentors, a number of activities and writing events were facilitated during the first term of its opening in partnership with the Learning Development team.

The Writing Mentors are a group of 12 undergraduate and postgraduate students who undertake paid shifts in the Writing Café on a weekly basis to provide peer support to fellow students. They come from a broad range of academic disciplines and levels of study, from level 4 to doctoral level, and were given a day's initial training in peer mentoring by a member of the Learning Development Unit at Aston University before beginning their post. Throughout the first term they engaged with a structured programme of on-going training and development activities, including: shadowing members of the Learning Development team and the English Language Centre, when consent was given; dyslexia awareness training; support and signposting; cultural awareness training and supporting students with revision and exam strategies. All of the students involved in this research were partners in the project, and therefore caution must be taken in regards to wider claims of Writing Mentors who are not considered as stakeholders in initiatives.

\section{Methodology}

The primary aim of the research was to investigate whether or not the Writing Mentors at the Writing Café benefited from participating in their role over the course of one academic term ( $6^{\text {th }}$ January 2014 to $28^{\text {th }}$ March 2014). The objectives of the research were to:

- Understand what benefits and challenges the Writing Mentors faced in their role.

- Understand how working in partnership with the Learning Development team impacted the Writing Mentors, if at all.

In line with the ethical approval obtained, purposive sampling was used as all of the Writing Mentors, a total of 12, were invited to take part in the study. Of the 12, 9 took part. The study adopted the action research philosophy in order to implement changes in the Learning Development team's practice, and a multi-methodology was employed to enable triangulation and data analysis as advocated by Bryman (2004). This included gathering a weekly reflective journal written by each of the Writing Mentors throughout the academic term, and conducting semi-structured interviews with 8 participants on $24^{\text {th }}$ April 2014 (one participant was unavailable for interview). Nominal data was also collected to establish if 
the Writing Mentors could be classified as students from widening participation backgrounds in accordance with the Office of Fair Access's definitions (OFFA, 2014).

The Writing Mentors were asked to complete reflective journal entries once a week, but the focus of those entries was not prescribed. Reflective journals were chosen as they can provide clues as to the importance of events for the participants and their attitudes about those events (Jacelon and Imperio, 2005). Another intention of the reflective journals was to understand the students' perspective with the researcher's influence being minimised as much as possible (Jacelon and Imperio, 2005). Maintaining a journal encouraged the participants to focus on activities and reflections that they valued (Jacelon and Imperio, 2005) whilst providing the researcher with the opportunity to explore these perspectives during the subsequent interview (Elliot, 1997; Zimmerman and Wieder, 1977). Semistructured interviews were also used as the standardisation of a number of questions increases data reliability whilst providing the opportunity to ask spontaneous questions (Drever, 1995). A total of seven structured questions were developed and asked to each participant.

The stages of data analysis included fully transcribing the audio-recorded interviews and reflective journals and conducting content driven thematic analysis on all of the texts (Braun and Clarke, 2006). This allowed for the identification and categorisation of relevant themes and patterns, thus allowing interpretation in a meaningful way. Initially, the audiorecorded interviews and reflective journals were reviewed several times to get an overall sense of the data. No pre-existing coding systems were used and an inductive approach to content analysis was undertaken. Initial themes or codes were identified and all data reviewed again. Themes were grouped together and checked for emerging patterns. After reading and re-reading the data and reviewing the interviews multiple times, five themes emerged: personal; teamwork, role boundaries, events and university awareness.

\section{Discussion}

The definitions of the themes that emerged from the thematic content analysis are as follows: 
- Personal - this refers to the perceived benefits reported by the Writing Mentors, including feeling happy, more confident and developing friendships.

- Teamwork - this is concerned with the benefits of working as a team of Writing Mentors, and in partnership with the Learning Development team.

- Role Boundaries - this refers to the negative or difficult experiences Writing Mentors faced when supporting fellow students in a new role.

- Events - this refers to a positive experience either running and organising an event or workshop, or participating in the event or training opportunity.

- University Awareness - this represents the Writing Mentors having more awareness of Plymouth University's culture, diversity, policy and ambition.

\section{Personal}

All participants discussed their perceived personal benefits of undertaking the role, including feeling happy and being more confident after having worked as a Writing Mentor. Although the findings might be constrained by the sample, as the Writing Mentors come from different backgrounds and may hold different expectations or have different levels of confidence, all participants described positive benefits to their self directly due to the role:

It's definitely given me confidence, something I haven't had for a very long time.

I've absolutely loved it...it's generally made me happier and confident, l've made a lot of friends and it's been a really good experience.

Seeing people come to these workshops quite sceptical and then having a really positive experience is great. It's often emotional, and for me it's made me happy and that is really rewarding.

A particular positive is the confidence I...[have] now. I've felt more secure in myself as a person [since undertaking work as a Writing Mentor]. That role gives you confidence when you can help someone.

It sounds a bit cheesy but it literally has changed my life. It's made me so much happier and taught me so much, and l've grown so much as a person. It's made me feel a lot more confident in myself. 
All of the participants in the study are from widening participation (WP) backgrounds, as identified through the gathering of nominal data, and although they can be classified as one group in this sense, as discussed above they all have different expectations and levels of confidence. This perception of personal achievement and increasing confidence is all the more beneficial as the Writing Café advertised its vacancies for Writing Mentors across the student body, and perhaps due to Plymouth University's large WP student body, all of those that undertook the role can be categorised in one or more of OFFA's definitions of under-represented groups in HE (2014); minority ethnic groups, disabled students, students from lower socio-economic groups and mature students. For Kennedy, a common characteristic in these students is a lack of confidence and he advocates for staff in HE institutions to find ways to engage and support these students (1997). It is possible that the Writing Café became a way to make contact with these students, supporting them to engage with HE through its partnership approach. By working in partnership with students there is the potential to support a greater sense of belonging and community (Healey et al., 2014), something specifically reported by one of the participants:

I'm a person that has been through a lot of hardship in my life and has made a lot of mistakes and for someone to give you a second chance and to believe in you makes you feel good about yourself...so personally it has given me the confidence to associate with other students and other mentors, something I haven't done up until working at the cafe... I haven't really felt part of the university until now and now I do that really should benefit all of us.

\section{Teamwork}

The students as partners approach respects students as co-creators of their learning experiences and has the potential to increase student engagement (Healey et al., 2014). Whilst engagement benefits all students, it can have a particularly positive effect on students from WP backgrounds (Pascarella and Terenzini, 2005) and can empower traditionally marginalised students to develop the authority and responsibility to co-develop a culturally sustainable pedagogy (Cook-Sather and Agu, 2013). Eight of the participants involved in the study discussed benefits of working in partnership with the Learning Development team, and the data suggests that the shared enthusiasm across the team encouraged and supported them to learn together: 
Learning Development is so encouraging and supportive. By shadowing them we are all learning together.

Working as part of the team has been the most positive thing as we are all working together on the same outcome. We all have the same goals and the same passion....and that's good.

It's so great to come together with likeminded people...it's also quite refreshing to be involved with younger people. As a mature student throughout my BA I never really associated with the younger crowds, yes in seminars we shared ideas, however I have had the opportunity to get to know these younger folk. This diversity is one of the great things about the Writing Café.

Shadowing XXXX was most educative: the approach to students' work was one of enquiring rather than telling. Once again, the relation to the student was very relaxed and dynamic so that, by the end of it, the students were amiably chatting as if you were not their mentor but a trusted friend. That's how we all feel about working with the Learning Development team, they listen, they question, we learn together.

By facilitating me, and the other mentors, to work as a really strong team the Writing Café has scurried its way to the peak of my favourite places in Plymouth.

What this week has shown me is that we are what we portray. To be aware of where we are, how we speak to and treat people. We are all important people... it is crucial to be student focused. We all work together as a team supporting students and each other. The Writing Café needs to be inviting so the students will want to come back and seek us mentors out again. It does have a positive vibe, a freshness, a newness and an excitement, of which I am pleased to be part of.

I feel our first social has had a tremendous impact on the growth and understanding and bonds between the team. I really appreciate being given the freedom to run with my ideas. Bonds have been formed between the team...this has led to us working together more effectively as a team due to a greater understanding and 
respect for each other's strengths and weaknesses. I hope that as the project grows I am presented with more of these responsibilities.

\section{Role boundaries}

Working together in partnership may have allowed the Writing Mentors to become involved in areas they would have traditionally been excluded from. By providing them with the freedom to initiate and run with their ideas, such as implementing social events and leading workshops, it was hoped they would actively engage in their learning and develop their identity as individual learners as well as part of a learning community (Healey et al., 2014). Instead of listening to the students' voice and responding accordingly, the Learning Development team gave the Writing Mentors the opportunity to explore areas they believed to be significant and supported them to recommend solutions and bring about change. In doing this it was hoped that the students could act as 'change agents' and 'active collaborators' rather than consumers (Dunne and Zandstra, 2011, pg. 4 foreword). The extracts overleaf suggest that the participants in this study were grateful for these opportunities and overall felt that the Learning Development team were also learning alongside themselves. One participant reported that:

It feels like we are a member of a community and we can make the changes we want to, rather than just the normal student body.

This participant perceived the 'normal student body' as those who were not engaged with questioning and having voice in institutional initiatives such as teaching and learning, assessment, research and inquiry and curriculum design, and were the 'consumers', instead of co-designers. Therefore, to this participant, the normal student body is unable to become part of any direct change. The partnership approach may have supported this student to feel they were responsible, and able to influence areas they believed to be significant, but had traditionally been excluded from. Whilst working in partnership appears to have been beneficial in relation to the team dynamics and power balances, the Writing Mentors also reported the frustrations they faced in undertaking the role. Partnership approaches can present 'challenges to existing ways of being, doing and thinking' (Healey et al., 2014, pg. 9) and four of the Writing Mentors discussed difficulties in defining their role boundaries on a number of occasions: 
Trying to understand and grasp what a mentor is, and how they [Writing Mentors] can help students to make [the experience with a student] the best they can has been difficult.

One of my first experiences mentoring was with an international student, it was challenging in that whilst there was a language barrier, there was also a difficulty in that the student just wanted a proof reader.

The main thing has been when international students come and ask about grammar and English. It's obviously quite hard when you have to tell someone no, especially when they've come to you for help so that's sometimes a tricky situation to deal with but it's quite a rare one. Signposting is crucial.

There have been some challenges. I had one girl come in with a piece of creative writing...she wanted me to tell her the plot of her story...I had to guide her to think of ideas without saying 'do this, do that'.

Trying to explain critical thinking to international students is hard...I had problems with it when I was writing reports in my first year. They just wanted the answers.

My student was an international pupil and the main challenge imposed on our session was a resultant language barrier and consequential misunderstanding during communication. That and they wanted a proof reader.

This highlights the importance of supporting the Writing Mentors with cultural diversity by sharing the practices of Learning Development more explicitly. As previously discussed, Learning Development at Plymouth University is often viewed as a skills team, mistaken for grammar experts or staff who can fix problems for failing students. Our Learning Developers often have to ensure they do not give answers, but rather support and encourage students to figure out what they would like to say, and act as a critical friend, or sounding board. This occurs with both home and international students, and the ability to navigate conversations that begin with a seemingly simple issue often lead to a much more valuable and constructive discussion. In a sense this can be seen as a threshold concept' of the profession (Meyer and Land, 2003) and the extracts above demonstrate how the Writing Mentors confronted their assumptions of others and their self to navigate 
through this threshold. While the comments suggest that the Writing Mentors are comfortable defining their boundaries, it is an area that has been challenging for them and additional support and dialogue is required. To ensure a successful partnership in this area, it is important that sensitivity to these tensions is adopted because out of the four Writing Mentors, only one seemed to be confident in navigating these discussions with students:

It began ostensibly with a request for referencing advice, specifically the issue of how to cite when paraphrasing. This resolved, I broadened the discussion....and began talking about how the student might want to develop their own voice.

They came to the café with the impression a Writing Mentor will proofread their work for grammar and language checks. They weren't confident in their writing so I had to explain in detail my role....and afterwards I helped them go through the argument in their report. It was a good session in the end.

\section{Events}

The Writing Mentors always work in pairs when they are on duty in the Writing Café, although they may individually peer support fellow students. Despite having another student around to discuss any problems with, the data suggests that four of the Writing Mentors faced difficulties in communicating their role to the students they were supporting. Whilst this occurred when dealing with peers on a one to one basis, there is no evidence that the same difficulties arose when running and organising events and workshops attended by a number of people:

This week has been quite a successful one. It has been decided that on the $1^{\text {st }}$ March three writing groups shall come together and have a collaborative writing night whereby people do readings and the mentors run the night. I think this will be great as it builds bridges in the community and gives people a chance to showcase their work.

It was an amazing experience [a 24 hour writing marathon], to organise and be a part of, that I might not otherwise have been able to have. It was such a good 
bonding experience for all of the mentors and was really nice to be able to extend our impact to the wider community by the fundraising that we did.

The 24 hour writing was a standout moment for me. Being part of it and having members of the community come in and encourage us. Listening to readers read their own work and seeing vulnerable people go out of their comfort zones to share their writing is amazing.

It is possible that because the number of events has exceeded the number of one to one sessions that took place in the Writing Café, and that the Writing Mentors were the initiators of many of these events, they were more invested in their success and confident in dealing with them. In addition to this, the data also demonstrates that the Writing Mentors worked as a team when setting up these events, perhaps offering each other support and social integration into the role. Perhaps the identity of the Writing Mentors as a cohesive group is currently stronger than that of each individual member, which is not surprising given the difficulty in identity formation in HE today (Scanlon et al., 2007).

\section{University awareness}

The final theme, which emerged from the data analysis, was university awareness. Four participants demonstrated a stronger awareness of the university, particularly in the field of Learning Development:

It's been fantastic as you are professionally supported and have opportunities to shadow either Learning Development Advisors or Dyslexia Advisors and mentors so you get to see more than you would if you were just a student.

The conference was great. It was really interesting to see that Learning Development isn't really just a little room... it's a whole network. It's a whole culture of people that are out there that are very intelligent and dedicated to what they do. They genuinely care about the student experience and about learning. That was powerful, seeing that connection with the wider academic world. 
I think that seeing what Learning Development is all about, the fact that it feels absolutely integrated with the student experience....it's about bettering yourself and that's exactly what university is about. That's been quite powerful for me.

I didn't know how many international students there are. And they have it hard. Really hard. Sitting down next to one who had fled from war really makes you think.

Of these 4 participants, 2 of them were provided with the opportunity to co-deliver academic papers with the Learning Development team at a national conference. This undoubtedly gave them a greater insight into the current practices and issues regarding Learning Development today, and provided them with the opportunity to gain a wider view of the HE system and the challenges it faces. Additionally, the data suggests that 3 of the Writing Mentors have started to understand the culture of British HE through the eyes of international students, something that may provide the platform for them to question practices, continue to develop their identities as students, and act as change agents.

\section{Conclusion}

This study set out to investigate the Writing Mentor's perception of the benefits and challenges associated with their role during one term at the Writing Café. The findings suggest that working with students as partners had a number of benefits including:

- Students felt able to make changes and run events they deemed important.

- Their perceived self-confidence increased and they became happier as a result of the work.

- Some were able to make connections between the work at the Writing Café and the institutions objectives as well as the aims of the wider academic community.

Whilst the findings were largely positive, it is also clear that future support should focus on role boundaries, continuing to support changing individual identities and peer supporting international students. It has also become apparent that integrating new Writing Mentors into the existing team will require attention and considerable thought to ensure they too feel like partners and are able to implement change. Recognition also needs to be made to the fact that being involved in the design of the project and forming the original community 
of practice may have helped some students feel a sense of ownership of the project, thus careful consideration of how the new Writing Mentors are introduced to the existing team is needed, to ensure they are supported in their role and valued as individuals, as well as part of the team.

The approach of working with students as partners and re-addressing power balances appears to have been a beneficial way of co-ordinating the project and supporting the Writing Mentors throughout their first term, and it could act as a case study for other institutions looking to initiate student-led activities as:

Engaging students and staff effectively as partners in learning and teaching is arguably one of the most important issues facing higher education in the $21^{\text {st }}$ century (Healey et al., 2014, pg. 7).

As the Writing Café moves from a pilot project to the next stage of its development, it will be crucial to reflect on the findings from this action research project and ensure the Writing Mentors are fully supported when working in partnership with the Learning Development team, particularly due to the ever increasing number of students accessing support there. Further research is needed to investigate to what extent the Writing Mentors support helps students visiting the café, for workshops, events and individual sessions. Additionally, research is currently being undertaken to investigate whether or not the physical space impacts the way students access support, and whether or not this has an effect on the nature of the conversations which take place in the alternative learning space that is the Writing Café.

\section{References}

Avery, S. and Bryan, C. (2001) 'Improving spoken and written English: from research to practice', Teaching in Higher Education, 6(2), pp. 169-182.

Bensimon, E. M. (2009) 'Foreword', in Harper, S. R. and Quaye, S. J. (eds.), Student Engagement in Higher Education. New York and London: Routledge, pp. xxi-xxvi.

Bhabha, H. (1994) The location of culture. New York: Routledge. 
Brauer, G. (2003) 'Centres for writing and reading - bridging the gap between university and school education', in Bjork, L., Brauer, G., Rienecker, L. and Jorgensen, P.S. (eds), Teaching Academic Writing in European Higher Education. London: Kluwer Academic, pp. 135-50.

Braun, V. and Clarke, V. (2006) 'Using thematic analysis in psychology', Qualitative Research in Psychology, 3(2), pp. 77-101.

Bryman, A. (2004) Social research methods. $2^{\text {nd }}$ edn. Oxford: Oxford University Press.

Cook-Sather, A. and Agu, P. (2013) 'Student consultants of colour and faculty members working together toward culturally sustaining pedagogy', in Groccia, J. E and Cruz, L. (eds.) To improve the academy: resources for faculty, instructional, and organisational development, Volume 32, pp. 271-285.

Crossan, B., Field, J., Gallacher, J. and Merrill, B. (2003) 'Understanding participation in learning for non-traditional adult learners: learning careers and the construction of learning identities', British Journal of Sociology of Education, 24(1), pp. 55-67.

Drever, E (1995) Using semi-structured interviews in small-scale research: a teacher's guide. Edinburgh: Scottish Council for Research in Education.

Dunne, E. and Zandstra, R. (2011) Students as change agents: new ways of engaging with learning and teaching in higher education. Bristol: A joint University of Exeter/ESCalate/Higher Education Academy Publication. Available from: http://escalate.ac.uk/8064 (Accessed: 8 June 2014).

Elliot, H. (1997) 'The use of diary methods in sociological research on health experience', Sociological Research Online, 2(2), pp. 33-38 [Online]. Available at: http://www.socresonline.org.uk/2/2/7.html (Accessed: 18 November 2015).

Ellis, M. (2004) The coffee-house: a cultural history. London: Weidenfeld \& Nicolson. 
Gallacher, J., Crossan, B., Field, J. and Merrill, B. (2002) 'Learning careers and the social space: exploring the fragile identities of adult returners in the new further education', International Journal of Lifelong Learning, 21(6), pp. 493-509.

Healey, M., Flint, A. and Harrington, K. (2014) 'Engagement through partnership: students as partners in learning and teaching in higher education, The Higher Education Academy, July 2014. Available at:

https://www.heacademy.ac.uk/sites/default/files/resources/engagement through pa rtnership.pdf (Accessed: 18 November 2015).

Hill, P., Tinker, A. and Catterall, S. (2010) 'From deficiency to development: the evolution of academic skills provision at one UK university', Journal of Learning Development in Higher Education, Issue 2, February, pp. 1-19.

Hilsdon, J. (2014) 'Peer learning for change in higher education', Innovations in Education and Teaching International, 51(3), pp. 244-254. DOI:

10.1080/14703297.2013.796709.

Ivanic, R. (1998) Writing and identity: the discoursal construction of identity in academic writing. Amsterdam: John Benjamins Publishing Company.

Jacelon, C. and Imperio, K. (2005) 'Participant diaries as a source of data in research with older adults', Qualitative Health Research, 15(7), pp. 991-997.

Jackson, C. (2003) 'Transitions into higher education: gendered implications for academic self-concept', Oxford Review of Education, 29(3), pp. 331-346.

Kennedy, H. (1997) Learning works: widening participation in further education. The Further Education Funding Council (FEFC). Available at: http://dera.ioe.ac.uk/15073/ (Accessed: 18 November 2015).

Lave, J. and Wenger, E. (1991) Situated learning: legitimate peripheral participation, Cambridge: Cambridge University Press. 
Lea, M. (1994) "I thought I could write till I came here”: student writing in higher education', in Gibbs, G. (ed.) Improving Student Learning: theory and practice. Oxford: Oxford Centre for Staff Development, pp. 216-226.

Lea, M., Street, B. (1997) Perspectives on academic literacies: an institutional approach. Swindon: Economic and Social Research Council (ESRC).

LearnHigher (2009) Learning to write: writing to learn. Academic writing: a literature review. Available at:

http://new.learnhigher.ac.uk/resources/files/academic writing literature.pdf (Accessed: 20 June 2014).

Meyer, J. H. F. and Land R. (2003) Threshold concepts and troublesome knowledge: linkages to ways of thinking and practising within the disciplines. Available at: http://www.etl.tla.ed.ac.uk/docs/ETLreport4.pdf

Moje, E. B. (2007) 'Developing socially just subject-matter instruction: a review of the literature on disciplinary literacy teaching', Review of Research in Education, 31(1), pp. 1-44.

Moje, E. B., Mclntosh-Ciechanowski, K., Kramer, K., Ellis, L., Carrillo, R. and Collazo, T. (2004). 'Working toward third space in content area literacy: an examination of everyday funds of knowledge and discourse', Reading Research Quarterly, 39(1), pp. 38-70.

Moore, S. (2003) 'Writers' retreats for academics: exploring and increasing the motivation to write', Journal of Further and Higher Education, 27(3) pp. 333-342.

Murray, N. and Kirton, B. (2006), 'An analysis of the current situation', in Davies, S., Swinburne, D. and Williams, G. (eds.) Writing matters: the Royal Literary Fund report on student writing in higher education. London: The Royal Literary Fund, pp. 7-13. 
National Committee of Inquiry into Higher Education (1997) Higher education in the learning society (the Dearing report). London: National Committee of Inquiry into Higher Education. Available at:

http://www.educationengland.org.uk/documents/dearing1997/dearing1997.html (Accessed: 18 November 2015).

Office for Fair Access (OFFA) (2014) Promoting Fair Access to Higher Education. Available at: https://www.offa.org.uk/press/frequently-asked-questions/\#groups (Accessed: 12 August 2014).

Pascarella, E. T. and Terenzini, P.T (2005) How college affects students: a third decade of Research, Volume 2. San Francisco, CA: Jossey-Bass

Plymouth University (2012) Strategy 2020. Plymouth, UK: Plymouth University. Available at:

https://www.plymouth.ac.uk/uploads/production/document/path/1/1667/PLYMOUTH UNIVERSITY STRATEGY 2020.pdf. (Accessed: 18 November 2015).

Russell, D.R. (2003) 'Preface', in Bjork, L., Brauer, G., Reinecker, L., and Jorgensen, P.S. (eds) Teaching academic writing in European higher education. London: Kluwer Academic Publishers.

Scanlon, L., Rowling, L., Weber, Z. (2007) 'You don't have an identity...you are just lost in a crowd: forming a student identity in the first-year transition to university', Journal of Youth Studies, 10(2), pp. 223-241.

Wenger, E. (1998) Communities of practice: learning, meaning and identity. Cambridge: Cambridge University Press.

Wingate, U. (2006) 'Doing away with 'study skills', Teaching in Higher Education, 11(4), pp. 457-469.

Yeats, R., Reddy, P., Wheeler, A., Senior, C., and Murray, J. (2010) 'What a difference a writing centre makes: a small scale study', Education + Training, 52(6/7), pp. 499507. 
Zimmerman, D. H. and Wieder, D. L. (1977) 'The diary: diary interview method', Urban Life, 5(4), pp. 479-498.

\section{Author Details}

Christie has worked in Higher Education for the past 5 years, and is a full time Learning Development Advisor at Plymouth University. She works with students across all disciplines and levels of study, with the aim of empowering them to achieve their best at university, both academically and personally.

She teaches on a wide variety of undergraduate and postgraduate programmes and supports academics to design engaging and interactive sessions embedding the values of Learning Development into the disciplines.

She is the co-founder and coordinator of an alternative learning space on the university's campus, the Writing Café, and is particularly interested in the complex relationship between space, learning and identity. She has carried out collaborative research and pedagogic work in the areas of curriculum development, learning space and policy, students' belonging and identity, and peer support. She is currently undertaking a professional Doctorate in Education (EdD) and uses this as a vehicle to interrogate her own practice and the changing practices of higher education institutions. 